\title{
DEVELOPMENT AND CHARACTERIZATION OF SUSTAINED RELEASE METHOTREXATE LOADED CUBOSOMES FOR TOPICAL DELIVERY IN RHEUMATOID ARTHRITIS
}

\author{
KARISHMA KAPOOR, VINAY PANDIT'1 ${ }^{1}$ UPENDRA NAGAICH ${ }^{*}$
}

\author{
*Amity Institute of Pharmacy, Amity University, Sector 125, Noida, UP 201313, ${ }^{1}$ Laureate Institute of Pharmacy, Kathog, Kangra 177101 \\ HP India \\ Email: unagaich@amity.edu
}

Received: 29 May 2019, Revised and Accepted: 06 Mar 2020

\begin{abstract}
Objective: Non-Steroidal Anti-Inflammatory Drugs (NSAIDs) are essential part of the administration of Rheumatoid Arthritis (RA). Methotrexate (MTX) is effective for tumor necrosis factor alpha (TNF-a) biologic agents, indicated only in minority of patients suffering from severe RA. MTX remains the "anchor drug" in the treatment of RA. For delivery improvement, novel pharmaceutical drug delivery system i.e. MTX-Cubosomes were developed.

Methods: Poloxamer 407 and Glycerol monooleate (Monoelin, MO) used and the formulation were characterized as a sustained release drug delivery system for Methotrexate. Different ratios of Monolein, Poloxamer 407 and water were used to develop the different cubosomes using homogenization and emulsification method. Characterization of formulations for morphology was performed and also particle size distribution by
\end{abstract} Transmission Electron Microscopy (TEM).

Results: Formulation showed the internal cubic structures of the vesicles. The particle size of the formulations was found to be ranging from 53.21 to $185.32 \mathrm{~nm}$, zeta potential of the formulations varied from-18.20-36.10 mV. The cubosomal formulation exhibited good entrapment efficiency along with high drug loading. Compatibility with the excipients was also established. An in vitro release study was done using Franz Diffusion cell indicated sustained release of the formulation at a rate of $1.25 \% / \mathrm{h}$. Cubosomes proved to be reliable system for sustained transdermal drug delivery system.

Conclusion: Methotrexate cubosomes is a novel medication delivery framework and in this examination it has been developed and characterized. The formulations were found to be promising in terms of its characterization parameters like particle size, zeta potential, entrapment efficiency, loading capacity, release kinetics, and stability, suitable for topical delivery.

Keywords: Rheumatoid arthritis, NSAIDs, Cubosomes, Methotrexate

(C) 2020 The Authors. Published by Innovare Academic Sciences Pvt Ltd. This is an open access article under the CC BY license (http://creativecommons.org/licenses/by/4.0/) DOI: http://dx.doi.org/10.22159/ijap.2020v12i3.36863. Journal homepage: https://innovareacademics.in/journals/index.php/ijap

\section{INTRODUCTION}

RA is an autoimmune system sickness related with cutting edge incapacity, foundational inconveniences, early passing, and financial costs [1]. RA is an affliction depicted by methods for intense and constant fundamental disease that incorporates the joints, and affects tissues and organs that comprise of veins, heart, skin, lungs, and muscles. The beginning and seriousness of infection are alterable and tricky. RA at first bears with weakness, musculoskeletal agony, and firmness and after certain weeks to months it develops to include joints. The little joints are influenced first, the little bones of the fingers than the bigger joints are influenced, winds up swollen, warm, and painful [2]. Morning firmness or stiffness is additionally the signs and manifestations of RA and proposes enthusiastic illness. The influenced individual for the most part characterizes gradualness or challenge in development [3].

It creates a fiery reaction of the synovium (synovitis) of synovial cells and the pannus improvement in the synovium. The pathology of the confusion once in a while prompts the decimation of articular ligament and ankylosis of the joints (wrists, shoulders, knees, lower legs and feet). RA can likewise affect different segments of the body in like manner joints and even delivers diffuse disease or irritation in the lungs, pericardium, pleura, and sclera, nodular sores, and in subcutaneous tissue. It is viewed as a systemic autoimmune system disease [4].

MTX is a robust anti-inflammatory and immunosuppressant drug that diminishes cell expansion, expanding adenosine discharge, and hinders catalysts of folate metabolism [21]. MTX adjusts the expression of cellular adhesion molecules, changes the generation of cytokines, and results on humoral reactions, and bone arrangement and affidavit [17] MTX is considered BCS class IV (Biopharmaceutics Classification System) medicate (hydrophobic medication with a low penetrability) [18] and is trying to manage because of the reality of instability and mild sensitivity [19]. The awful pharmacokinetics and assurance issues of the MTX limit its therapeutic impacts. The dangerous results on oral and gastrointestinal mucosa incorporate, stomatitis and seeping of the mucous films of the mouth or in gastrointestinal (GI) tract, ulcerations, enteritis and stomach trouble by method for conventional medication transport routes [29]. Oral absorption likewise is very low [3-6] and because of its concise complete half-life, [12] the transdermal use of MTX is by all accounts increasingly invaluable to accomplish good aid from pain.

Cubosomes, cubic portion is an intriguing method for medication transport comprising of a bent relentless lipid bilayer reaching out in three dimensions and keeping separated two consistent systems of water channels [13-16]. It can encase hydrophilic, amphiphilic, and hydrophobic components going from little small-molecularweight drugs to proteins, peptides, amino acids, and nucleic acids [16]. Bi-phasic cubic stages are available in regular lipids, cationic [24] and nonionic surfactants, [25] and polymer framework, The primary pioneer of cubosome development is monoolein which is a blend of the oleic glycerides and other unsaturated fats comprises of the monooleate [26-28]. Cubic phase of cubosomes [29] as a result of its little pore size (5-10 nm) has an application for controlled release; and furthermore can solubilize hydrophobic, hydrophilic, and amphiphilic molecules; and has biodegradable activity [30]. It is emphatically bioadhesive [31] with great compatibility with topical and mucosal deposition and conveys dynamic fixings due to its skin penetration enhancing capability [32].

Hence, the objective behind this study was to formulate topical cubosomes, novel delivery system that could help in Rheumatoid Arthritis improving absorption to the skin and simultaneously reduce the systemic diffusion of the skin-absorbed drug.

\section{MATERIALS AND METHODS}

\section{Materials}

Methotrexate was a kind gift from IPC, India. Poloxamer 407, MO was obtained from Gattefose, France. Dialysis membrane (molecular 
weight cut-off $12,000 \mathrm{~g} /$ mole) was purchased from Sigma Chemical Company (Sigma-Aldrich Corp., St. Louis, MO, USA). Polyvinyl alcohol, Potassium dihydrogen phosphate and disodium hydrogen phosphate was purchased from Sigma-Aldrich (Sigma-Aldrich Co., St. Louis, MO, USA). All other chemicals used were of analytical grade.

\section{Methods}

Preparation of methotrexate-loaded cubosomes nanoparticles

Cubosomes Dispersions were made by emulsification of the cubelike lipid part comprising of MO and Poloxamer 407 in water containing PVA 20 as appeared in table 1 . The cubosomes were shaped by softening MO and Poloxamer 407 with the guide of hot plate kept up at $60{ }^{\circ} \mathrm{C}(\mathrm{MLH})$. At that point, the medication was dissolved down inside the melted blend. Distilled water containing $2.5 \% \mathrm{w} / \mathrm{w}$ PVA (low viscous cube-like part is accomplished by utilizing natural solvents, preheated at indistinguishable temperature) was added to the melted blend underneath mechanical mixing at $500 \mathrm{rpm}$. Dispersions were kept up under blending at temperature for $2 \mathrm{~h}$ to harden the lipid. The Dispersions were exposed to mixing at 15000 cycles for each min at $60^{\circ} \mathrm{C}$ for $1 \mathrm{~min}$ (Heidolph Homogenizers, Silent gadget M, and Germany). When the formulations were cooled, they were kept up at room temperature in glass vials.

Table 1: Formulation table

\begin{tabular}{|c|c|c|c|c|c|}
\hline S. No. & Formulation code & PLX: MO ratio & PLX (\%w/w) & MO $(\% w / w)$ & Plx and MO: water \\
\hline 1) & F1 & - & 0.00 & 4.76 & $1: 20$ \\
\hline 2) & $\mathrm{F} 2$ & $1: 6$ & 0.68 & 4.08 & $1: 20$ \\
\hline 3) & F3 & $1: 4$ & 0.96 & 3.80 & $1: 20$ \\
\hline 4) & F4 & $1: 2$ & 1.58 & 3.18 & $1: 20$ \\
\hline 5) & F5 & - & 0.00 & 9.10 & $1: 10$ \\
\hline 6) & F6 & $1: 6$ & 1.30 & 7.80 & $1: 10$ \\
\hline 7) & F7 & $1: 4$ & 1.82 & 7.28 & $1: 10$ \\
\hline 8) & F8 & $1: 2$ & 3.04 & 6.06 & $1: 10$ \\
\hline 9) & F9 & - & 0.00 & 16.66 & $1: 5$ \\
\hline 10) & F10 & $1: 6$ & 2.38 & 14.28 & $1: 5$ \\
\hline 11) & F11 & $1: 4$ & 3.34 & 13.32 & $1: 5$ \\
\hline 12) & F12 & $1: 2$ & 5.56 & 11.10 & $1: 5$ \\
\hline
\end{tabular}

\section{Characterization of methotrexate-loaded cubosomes}

\section{Determination of $\mathrm{pH}$}

Digital pH meter (Mettler Toledo, Langacher, Switzerland) was used for measuring the $\mathrm{pH}$ of the formulated Cubosomes. For this, each formulation was taken sufficiently to dip the electrode accurately and it was kept for 5 min to stabilize $(\mathrm{n}=6)$.

\section{Rheological behavior}

The rheological conduct of MTX-loaded cubosomes was discovered utilizing cone and plate rheometer (Brookfield DV3THB cone/plate rheometer) kept up at $25 \pm 2{ }^{\circ} \mathrm{C}$ and revolution were extended straightly from 0.5 to $200 \mathrm{rpm}$ every moment. The MTX cubosomes conduct was investigated utilizing various models [21].

\section{Drug excipients compatibility studies}

The drug compatibility with polymer was determined with the help of Fourier transform infrared (FTIR) spectra of Methotrexate and Methotrexate-loaded cubosomes were determined by using Perkin Elmer RX1 model. The pellets were prepared by gently mixing freeze dried formulation (1 mg) with $200 \mathrm{mg}$ of potassium bromide and compacting at high pressure. The pellets thus prepared were scanned at a resolution of $4 \mathrm{~cm}-1$ from 400 to $4000 \mathrm{~cm}-1$ [33].

\section{Shape and surface morphology}

The MTX cubosomes was observed under TEM to determine the surface morphology and size of the formulation. The formulation was diluted 50 times with double distilled water and stained negatively by phosphotungstic acid and then dried on the carbon coated grid. Excess of Phosphotungstic was removed using filter paper. Finally it was observed using Morgagni 268D (magnification x 250 000, Fei Electron Optics, Netherlands) transmission electron microscope [21].

\section{Particle size, particle size distribution, polydispersity index (PDI) and zeta potential}

Cubosomes formulations were measured for the Particle size and its distribution, PDI and zeta potential of by Dynamic Light Scattering using Zetasizer (NanoZS90, Malvern Instruments Ltd. Worcestershire, UK). It was determined at a temperature of $25{ }^{\circ} \mathrm{C}$ and $90^{\circ}$ fixed angle. Before the measurement, one drop of the sample $(n=6)$ was taken from each selected formulation and diluted in $10 \mathrm{ml}$ of the dispersion medium (distilled water) [21].

\section{Entrapment efficiency and drug loading}

Cubosomes entrapment efficiency and drug loading were determined using high-speed centrifugation (Sigma 3K30, Osteorode am Harz, Germany) for $15 \mathrm{~min}$ at $15000 \mathrm{rpm}$. Supernatant was separated once centrifugation is done and filtered using Millipore VR membrane $(0.2 \mu \mathrm{m})$ [33]. Required dilution was done and it was analyzed $(n=6)$ by HPLC [23] to examine MTX content at $303 \mathrm{~nm}$. The entrapment efficiency (\%) and drug loading was calculated by using the following equation

$$
\begin{gathered}
\text { Entrapment Efficiency }(\% \mathrm{w} / \mathrm{w})=\frac{\text { Amount of Encapsulated Drug }}{\text { Total amount of the drug }} \mathrm{X} 100 \\
\text { Drug Loading }(\% \mathrm{w} / \mathrm{w})=\frac{\text { Amount of Encapsulated Drug }}{\text { Total amount of cubosomes }} \mathrm{X} 100
\end{gathered}
$$

\section{In vitro drug release studies}

The MTX releases from cubosomes across dialysis cellulose membrane (molecular weight cutoff $12000 \mathrm{~g} / \mathrm{mole}$ ) were performed by mounting it on vertical Hanson Franz diffusion cell system. The donor medium consisted of $1 \mathrm{~g}$ of vehicle containing Methotrexate. The diffusion area available between the cells was $1.785 \mathrm{~cm} 2$. The receptor compartment was filled with phosphate buffer ( $\mathrm{pH}$ 7.4). The receptor medium was stirred at $200 \mathrm{rpm}$ and the temperature was maintained at $37 \pm 0.5^{\circ} \mathrm{C}$. At fixed time intervals the receptor solution was sampled $(n=6)$ and the receptor compartment replaced with fresh buffer simultaneously for the maintenance of sink condition. The withdrawn samples were analyzed using HPLC [34].

\section{Release kinetics}

The drug release kinetics of Methotrexate Cubosomes was studied; the in vitro drug release study data was fitted to various kinetic models like, Higuchi matrix model, Hixon Crowell model, Korsmeyer-Peppas model and zero-order, first-order model. For each model, the correlation coefficient (R2) was calculated. The best fit model for the drug release was that giving R2 never to 1 was selected $[35,36]$.

\section{Stability studies}

The stability studies of the finalized formulations were done on the basis by ICH Q1A (R2) guidelines [45]. The samples of Methotrexate loaded cubosomes were stored under the following temperatures:
a. $25 \pm 2{ }^{\circ} \mathrm{C} / 65 \pm 5 \% \mathrm{RH}$
b. $40 \pm 2{ }^{\circ} \mathrm{C} / 75 \pm 5 \% \mathrm{RH}$; 
in stability chambers (Thermolab, Mumbai, India) for 6 mo. Withdrawn samples at different time intervals i.e. 0, 1, 2, 3 and 6 mo were analyzed for particle size distribution, PDI, Entrapment efficiency, drug loading and phase separation [37].

\section{RESULTS AND DISCUSSION}

\section{Preparation of methotrexate cubosomes}

The MTX cubosomes were prepared according to the plan referenced in table 1 . Surfactants, that were used in the plan of cubosomes, are poloxamer 407 of every an exceedingly focus differ somewhere in the range of 0 and $20 \% \mathrm{w} / \mathrm{w}$ with respect to the scatter part. The grouping of the monoglyceride/surfactant blends normally takes between $2.5 \%$ and $15 \% \mathrm{w} / \mathrm{w}$ with respect to the whole weight of the scattering. Polyvinyl Alcohol (PVA) utilized despite poloxamer as a balancing out administrator of the dispersion. PVA structures little particles having uniform allocation. Also, it produces particles that are simply coursed in liquid medium. Stabilizers are routinely intertwined inside the cubosomal dispersion to change its surface properties and consequently invigorate. The modification of cubosomes nanoparticles by poloxamer 407 occurred utilizing surface adsorption of the polypropylene oxide copolymer's hydrophobic moieties into the outside surface of the cubosomes nanoparticles.

\section{Characterization of MTX cubosomes}

\section{Determination of $\mathrm{pH}$}

The $\mathrm{pH}$ of all the prepared cubosomes was measured (table 2) to ensure that it doesn't affect the $\mathrm{pH}$ of the skin when applied topically. $\mathrm{pH}$ was measured to ensure that there is no irritation effect of the cubosomes on the skin.

Table 2: Characterization parameters of MTX cubosomes (mean $\pm S D ; n=6$ )

\begin{tabular}{|c|c|c|c|c|c|c|c|c|}
\hline $\begin{array}{l}\text { S. } \\
\text { No. }\end{array}$ & $\begin{array}{l}\text { Formula-tion } \\
\text { code }\end{array}$ & pH & $\begin{array}{l}\text { Particle size } \\
(\mu \mathrm{m})\end{array}$ & $\begin{array}{l}\text { Zeta potential } \\
(\mathrm{mV})\end{array}$ & $\begin{array}{l}\text { Entrapment } \\
\text { efficiency \% }\end{array}$ & $\begin{array}{l}\text { Loading } \\
\text { capacity (\%) }\end{array}$ & $\begin{array}{l}\text { Viscosity } \\
\text { (cp) }\end{array}$ & PDI \\
\hline 1 & F1 & $6.62 \pm 0.01$ & $185.32 \pm 12.10$ & $-18.20 \pm 1.27$ & $64.39 \pm 0.94$ & $11.22 \pm 1.34$ & $2.93 \pm 0.21$ & $0.754 \pm 0.03$ \\
\hline 2 & $\mathrm{~F} 2$ & $6.41 \pm 0.05$ & $93.90 \pm 3.90$ & $-33.95 \pm 2.19$ & $79.44 \pm 0.81$ & $5.81 \pm 8.13$ & $2.99 \pm 0.13$ & $0.391 \pm 0.02$ \\
\hline 3 & F3 & $6.88 \pm 1.10$ & $68.32 \pm 1.32$ & $-31.75 \pm 0.92$ & $80.31 \pm 0.72$ & $6.41 \pm 9.28$ & $3.14 \pm 0.17$ & $0.427 \pm 0.03$ \\
\hline 4 & F4 & $6.71 \pm 1.40$ & $23.21 \pm 0.89$ & $-31.85 \pm 0.78$ & $88.95 \pm 0.61$ & $13.31 \pm 2.13$ & $3.36 \pm 0.24$ & $0.124 \pm 0.03$ \\
\hline 5 & F5 & $6.42 \pm 2.60$ & $154.11 \pm 11.94$ & $-32.70 \pm 0.14$ & $60.39 \pm 0.24$ & $12.01 \pm 0.36$ & $3.41 \pm 0.13$ & $0.652 \pm 0.05$ \\
\hline 6 & F6 & $6.32 \pm 1.90$ & $168.75 \pm 3.72$ & $-32.35 \pm 0.49$ & $74.89 \pm 0.90$ & $6.59 \pm 6.32$ & $3.37 \pm 0.31$ & $0.331 \pm 0.03$ \\
\hline 7 & F7 & $6.68 \pm 2.40$ & $143.56 \pm 10.94$ & $-31.00 \pm 0.71$ & $77.62 \pm 0.53$ & $6.46 \pm 0.29$ & $4.13 \pm 0.18$ & $0.215 \pm 0.06$ \\
\hline 8 & F8 & $6.94 \pm 1.30$ & $130.71 \pm 8.35$ & $-33.95 \pm 0.49$ & $78.49 \pm 0.42$ & $8.89 \pm 4.23$ & $4.09 \pm 0.41$ & $0.391 \pm 0.02$ \\
\hline 9 & F9 & $6.65 \pm 1.9$ & $121.32 \pm 9.72$ & $-28.20 \pm 0.14$ & $60.99 \pm 0.94$ & $10.92 \pm 2.19$ & $6.63 \pm 0.48$ & $0.731 \pm 0.03$ \\
\hline 10 & F10 & $6.39 \pm 2.4$ & $78.21 \pm 5.47^{*}$ & $-33.60 \pm 0.28$ & $69.37 \pm 0.72$ & $7.10 \pm 0.31$ & $73.91 \pm 4.3$ & $0.312 \pm 0.01$ \\
\hline 11 & F11 & $6.92 \pm 0.8$ & $82.52 \pm 6.11$ & $-36.10 \pm 2.97$ & $70.63 \pm 0.44$ & $7.52 \pm 7.32$ & $79.97 \pm 4.9$ & $0.286 \pm 0.03$ \\
\hline 12 & F12 & $6.77 \pm 1.4$ & $83.32 \pm 6.28$ & $-32.70 \pm 0.99$ & $76.12 \pm 0.52$ & 7.912 .51 & $84.32 \pm 5.3$ & $0.329 \pm 0.03$ \\
\hline
\end{tabular}

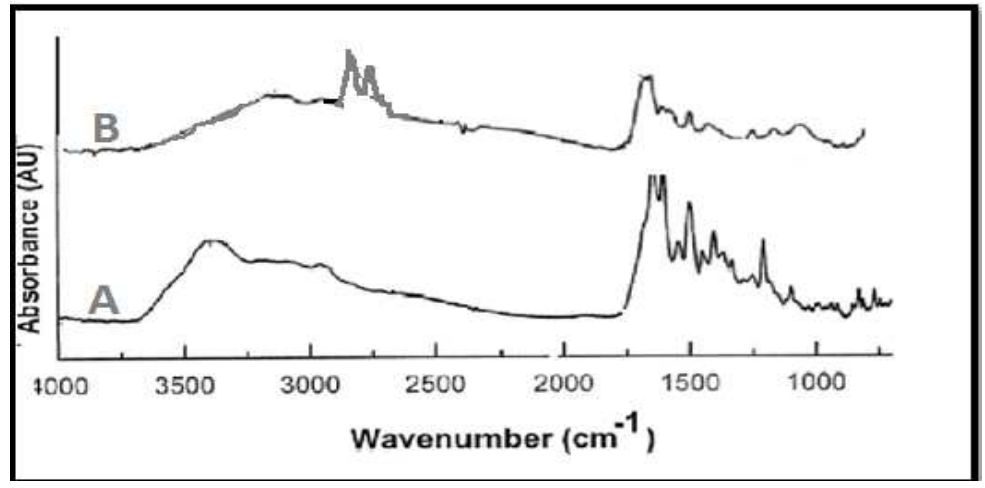

Fig. 1: FTIR image showing A) Methotrexate standard B) Methotrexate loaded cubosomes

\section{Rheological behavior}

The rheological behavior of the formulations was assessed to study the spreadability of the formulation and its residence for longer time. Increased concentration of Monolein and Poloxamer 407 showed better like consistency that increases the formulation viscosity (table 2). All the formulations have viscosities in the range that will provide better penetration.

\section{Drug excipients compatibility studies}

FTIR Spectroscopy of Methotrexate and Methotrexate loaded Cubosomes is presented in fig. 1. Strong and characteristic absorbance can be seen with Standard Methotrexate showing IR peaks at $1644 \mathrm{~cm}-1$ and $1603 \mathrm{~cm}-1$. Absorption peaks between 2500 $\mathrm{cm}-1$ and $3000 \mathrm{~cm}^{-1}$ indicative of unchanged excipients property. Spectra of cubosomes altered with Methotrexate show expanded absorbance at $1600 \mathrm{~cm}-1$ and the presence of another top at 1490 $\mathrm{cm}-1$ demonstrates the nearness of Methotrexate on the cubosomes. The intensity and the number of the peaks were found to be reduced suggesting possible interactions of the excipients with Methotrexate thereby reducing the crystalline nature and making the drug amorphous helpful in better absorption.

\section{Shape and surface morphology}

The surface morphology and mean distance across of the Methotrexate stacked cubosomes was imaged utilizing TEM. TEM pictures demonstrated nearly cube shape like surface of the detailing with uniform distribution for example $<200 \mathrm{~nm}$ (table 2) and it supported the molecule size estimation by the zetasizer. The outcomes demonstrate the particles were consistently appropriated and isolated from one another. Decreased molecule size of the definition F4 was because of the nearness of higher grouping of Poloxamer 407 which was adsorbed on surface going about as a covering layer that balances out the little cubosomes nanoparticles surface [21]. Decreased Poloxamer concentration brought about the expansion of molecule size which was because of the increment in interfacial pressure consequently bringing about aggregation expanding the molecule size. All the cubosomes at the magnification as high as $250000 \mathrm{x}$ were found not circular or round, they showed a cube like structure. TEM photomicrograph of the MTX loaded cubosomes is given in fig. 2 . 

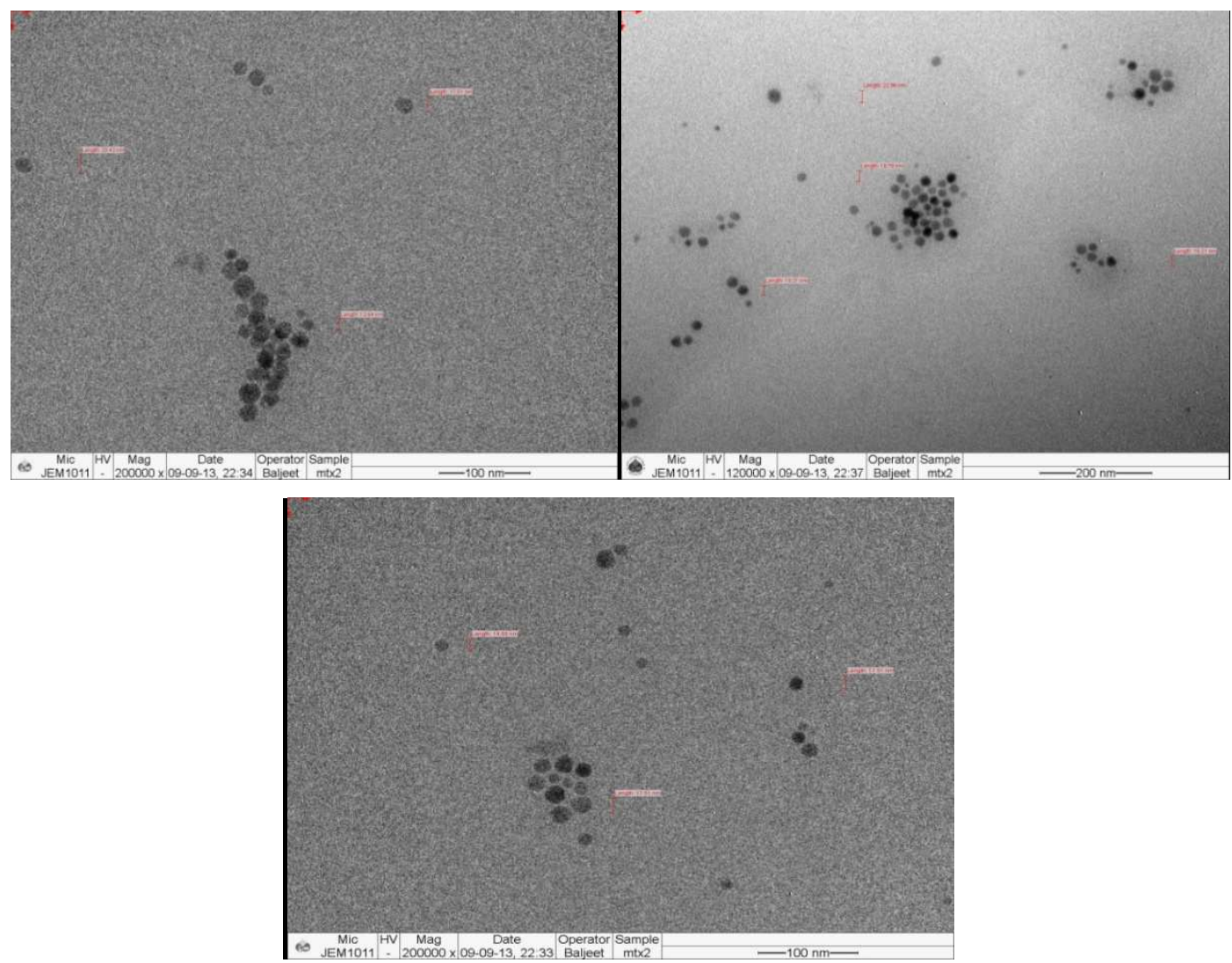

Fig. 2: Transmission electron microscopy images

\section{Particle size and polydispersity index}

The particle size of the formulations was found to be ranging between $53.21 \pm 0.8 \mathrm{~nm}$ to $185.32 \pm 12.1 \mathrm{~nm}$ (fig. 3) and PDI was found ranging from $0.214 \pm 0.03$ to $0.754 \pm 0.03$ (table 2).
Reduction in the surface tension between the lipid phase and the aqueous phase due to increase in the surfactant concentration might have lead to reduction of particle size. High surfactant concentration has also caused reduction in the steric hinderances [36, 37].

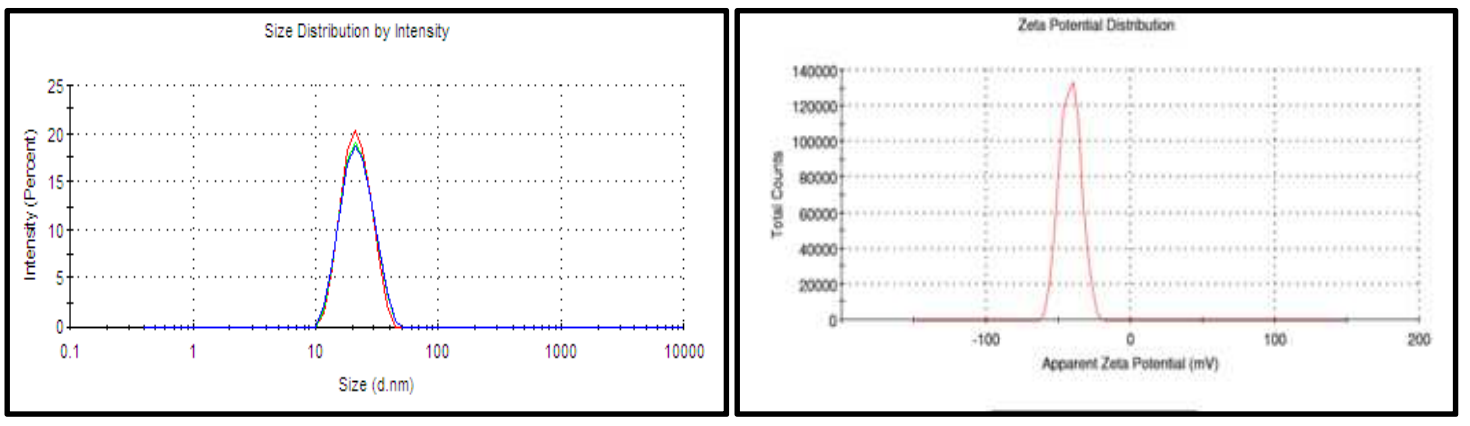

Fig. 3: Size distribution and zeta potential of cubosome

Zeta Potential of the formulations were found ranging from$18.20 \pm 1.27$ to $-33.95 \pm 2.19(\mathrm{n}=6)$ (table 2). Zeta potential indicates the stability of the dispersed particles in dispersion medium. High zeta potential shows high repulsion between the particles and particle aggregation is less likely to occur. A negative value of the zeta potential shows that formulations have good stability and dispersion quality.

\section{Entrapment efficiency and drug loading}

Different formulations were differentiated by determining the amount of drug incorporated in the formulation. The encapsulation efficiency of the formulations was found between $60.39 \pm 0.24$ and $88.95 \pm 0.61 \%$ (table 2). As the drug is lipophilic in nature it is found that the encapsulation efficiency was high. The drug loading capacity was found to be varying from $5.81 \pm 8.13$ to $12.01 \pm 0.36 \%$. Binary lipid matrices showed high loading and entrapment efficiency of the cubosomes [24].

\section{In vitro drug release}

In vitro drug release study profile of the cubosomes in the initial stage showed (fig. 4) controlled release upon contact with bulk release media. No burst drug release indicated the entrapment of the drug in the lipid layer and MTX slow diffusion. The hydrophobic drug in the external layer may partition through the polymer phase to the cubic phase. The drug release rate of all the formulation was observed varying from 1.55-1.89 \%/h showing a greater potential for the sustained release pattern of the cubosomes nano-formulation whereas gel showed a release of $23 \% / h$. Cubosomes showed a 
controlled drug release with $\mathrm{t}_{50}$ approximately $16 \mathrm{~h}$. The cumulative release percent almost achieved $100 \%$ after $48 \mathrm{~h}$, showing a complete release ability of formulation. Formulations F3 and F4 showed better release, droplet size and other characteristic properties. This pattern of slow release of the drug can be related to the slow expulsion due entrapment of the drug [38].

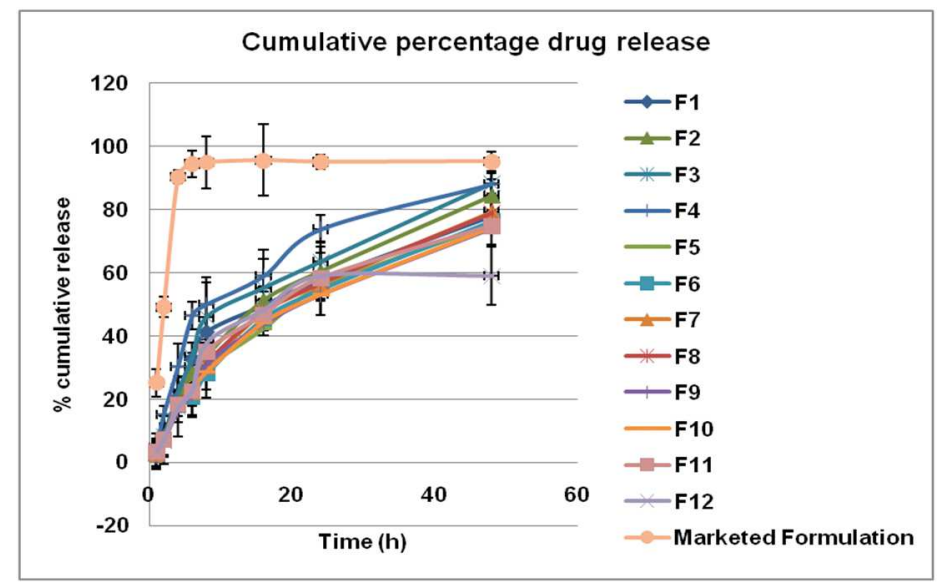

Fig. 4: In vitro drug release profile of MTX cubosomes and MTX Gel (mean $\pm S D ; n=6)$
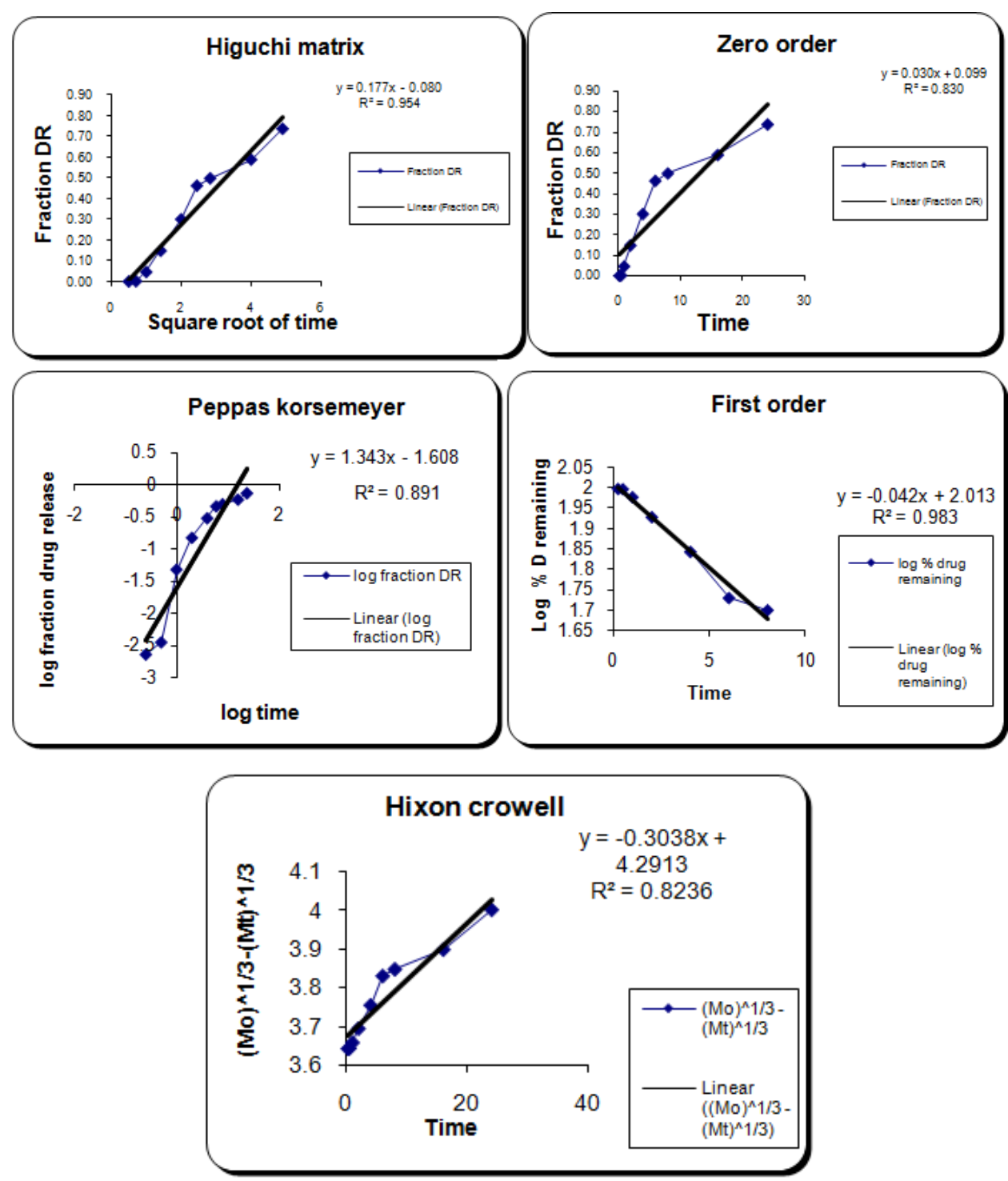

Fig. 5: Drug release kinetics of various models (mean $\pm S D ; n=6$ ) 


\section{Release kinetics}

The acquired in vitro release information was joined into different release kinetic models. The Highest estimation of the correlation coefficient was watched for the Higuchi matrix model (R2=0.9959) and it pursues non-fickian discharge. Higuchi depicts the drug release as a diffusion mechanism dependent on the Fick's law, contingent upon the square foundation of time. [39] This connection can be utilized to portray the drug dissolution from different sorts of altered or controlled release pharmaceutical dosage forms (fig. 5) [38].

\section{Stability studies}

The developed Methotrexate cubosomes were observed for particle size distribution, phase separation, Precipitation, \% Entrapment efficiency and \% Drug loading after keeping the product in specified conditions (table 3).

Table 3: Stability data (mean $\pm S D ; n=6)$

\begin{tabular}{|c|c|c|c|c|c|c|c|}
\hline Condition & Time & Phase separation & Precipitate & Particle size \pm SD & PDI \pm SD & \% Entrapment & \% Drug loading \\
\hline Initial & 0 & No & No & $78.45 \pm 0.42$ & $-30.42 \pm 0.11$ & $87.28 \pm 0.51$ & $14.40 \pm 4.21$ \\
\hline \multirow{2}{*}{$25 \pm 2{ }^{\circ} \mathrm{C} / 65 \pm 5 \% \mathrm{RH}$} & $3 \mathrm{M}$ & No & No & $69.32 \pm 5.31$ & $-31.26 \pm 0.48$ & $85.72 \pm 4.36$ & $13.37 \pm 3.91$ \\
\hline & $6 \mathrm{M}$ & No & No & $95.18 \pm 1.42$ & $-30.77 \pm 8.22$ & $83.37 \pm 0.42$ & $13.04 \pm 6.31$ \\
\hline \multirow[t]{2}{*}{$40 \pm 2{ }^{\circ} \mathrm{C} / 75 \pm 5 \% \mathrm{RH} ;$} & $3 \mathrm{M}$ & No & No & $102.48 \pm 4.71$ & $-29.46 \pm 0.11$ & $80.50 \pm 3.17$ & $12.94 \pm 4.20$ \\
\hline & $6 \mathrm{M}$ & No & No & $95.18 \pm 1.42$ & $-29.42 \pm 5.15$ & $76.20 \pm 4.19$ & $12.90 \pm 3.21$ \\
\hline
\end{tabular}

It was found that the formulation remained stable during 6 mo of stability studies. According to the results received, the kinetic analysis showed that the degradation of Methotrexate was found to follow zero-order reaction for the cubosomes formulation F4, based on the values of the correlation coefficient ( $\mathrm{r}$ ).

\section{CONCLUSION}

MTX is the best helpful specialist accessible to treat an assortment of malignancies, for example, non-Hodgkin's lymphoma, osteosarcoma, choriocarcinoma, lymphocytic leukemia, and head, neck, and bosom diseases. Utilized against non-neoplastic conditions, for example, serious psoriasis and immune system illnesses, for example, RA. Methotrexate cubosomes are additionally a novel medication conveyance framework and in this examination, it has been created and contemplated. The created conveyance framework is viewed as a means of fruitful treatment of rheumatoid as it gives controlled conveyance of the medication in human by means of the noninvasive skin course with additionally continuing, less successive dosing.

\section{FUNDING}

Nil

\section{AUTHORS CONTRIBUTIONS}

All the authors have contributed equally.

\section{CONFLICT OF INTERESTS}

\section{Declared none}

\section{REFERENCES}

1. Shah JC, Sadhale Y, Chilukuri DM. Cubic phase gels as drug delivery systems. Adv Drug Delivery Rev 2001;47:229-50.

2. Cotran R, Kumar V, Collins T. Robbins pathologic basis of disease. 6th Ed. Philadelphia PA: WB Saunders Company; 1999.

3. Lineker S, Badley E, Charles C. Defining morning stiffness in rheumatoid arthritis. J Rheumatol 1999;26:1052-7.

4. Aida Turturro Brings RA. Awareness Campaign to Philadelphia. Market Wire; 2005.

5. Lozada CJ, Firestein GS. Management of osteoarthritis. Kelley's Textbook of Rheumatology. 8th ed. Vol. 2. Philadelphia: Saunders Elsevier; 2009. p. 1563-77.

6. Firestein GS. Etiology and pathogenesis of rheumatoid arthritis. Kelley"s Textbook of rheumatology. 7th ed. Philadelphia: WB Saunders; 2005. p. 996-1042.

7. Rothschild BM, Rothschild C, Helbling M. Unified theory of the origins of erosive arthritis: conditioning as a protective/directing mechanism. J Rheumatol 2003;30:2095-102.

8. Spector TD. Rheumatoid Arthritis. Rheum Dis Clin North Am 1990;16:513-37.

9. Turesson C, O'Fallon WM, Crowson CS, Gabriel SE, Matteson EL. Extra-articular disease manifestations in rheumatoid arthritis: incidence trends and risk factors over $46 \mathrm{y}$. Ann Rheum Dis 2003;62:722-7.
10. Goldring SR. A 55 y old woman with rheumatoid arthritis. JAMA 2005;283:524-31.

11. Rothschild BM, Turner KR, Deluca MA. Symmetrical erosive peripheral polyarthritis in the late archaic period of Alabama. Science 1998;241:1498-501.

12. Silman AJ, Macgregor AJ, Whiting S. Twin concordance rates for rheumatoid arthritis: results from a nationwide study. $\mathrm{Br} \mathrm{J}$ Rheumatol 1993;32:903-7.

13. Lee KW, Nguyen TH, Hanley T, Boyd BJ. Nanostructure of liquid crystalline matrix determines in vitro sustained release and in vivo oral absorption kinetics for hydrophilic model drugs. Int J Pharm 2009;365:190-9.

14. Caffrey M. A lipid's eye view of membrane protein crystallization in mesophases. Curr Opin Struct Biol 2000;10:486-97.

15. Pan X, Han K, Peng X. Nanostructured cubosomes as advanced drug delivery system. Curr Pharm Des 2013;19:6290-7.

16. SL Morgan, RA Oster, JY Lee, GS Alarcon, JE Baggott. The effect of folic acid and folinic acid supplements on purine metabolism in methotrexate-treated rheumatoid arthritis. Arthritis Rheumatism 2004;50:3104-11.

17. Trotta M, Peira E, Carlotti ME, Gallarate M. Deformable liposomes for dermal administration of methotrexate. Int J Pharm 2004;270:119-25.

18. Amidon GL, Lennernas H, Shah VP, Crison JR. A theoretical basis for a biopharmaceutic drug classification: the correlation of in vitro drug product dissolution and in vivo bioavailability. Pharm Res 1995;12:413-20.

19. Morsi NM, Abdelbary GA, Ahmed MA. Silver sulfadiazine based cubosome hydrogels for topical treatment of burns: development and in vitro/in vivo characterization. Eur J Pharm Biopharm 2014;86:178-89.

20. Salah S, Mahmoud AA, Kamel AO. Etodolac transdermal cubosomes for the treatment of rheumatoid arthritis: ex vivo permeation and in vivo pharmacokinetic studies. Drug Delivery 2017;24:1, 846-56.

21. O'dell JR, Leff R, Paulsen G. Treatment of rheumatoid arthritis with methotrexate and hydroxychloroquine, methotrexate and sulfasalazine, or a combination of the three medications: results of a two-year, randomized, double-blind, placebocontrolled trial. Arthritis Rheum 2002;46:1164-70.

22. Alice R Oliveira, Lilia B Caland, Edilene G Oliveira, Eryvaldo ST Egito, Matheus FF Pedrosa, Arnobio A Silva Junior. HPLC-DAD and UV-Vis spectrophotometric methods for methotrexate assay in different biodegradable microparticles. J Brazilian Chem Soc 2015;26:649-59.

23. Strom P, Anderson DM. The cubic phase region in the system didodecyldimethyl-ammonium bromide-water-styrene. Langmuir 1992;8:691-709.

24. Lynch ML, Kochvar KK, Burns JL, Laughlin RG. Novel process for producing cubic liquid crystalline nanoparticles (Cubosomes). Langmuir 2000;16:3537-42. 
25. Engstrom S, Larsson K, Lindman B. Controlled release bioact. Mater 1998;15:105-6.

26. Engstrom S, Lindahl L, Wallin R. A study of polar lipid drug systems undergoing a thermoreversible lamellar-to-cubic phase transition. Engblom J Int J Pharm 1992;86:137-45.

27. Boyle E, German JB. Monoglycerides in membrane systems. Crit Rev Food Sci Nutr 1996;36:785-805.

28. Drummond CJ, Fong C. Surfactant self-assembly objects as novel drug delivery vehicles. Curr Opin Colloid Interface Sci 2000;4:449-56.

29. Lee SJ, Kavanaugh A. Pharmacological treatment of established rheumatoid arthritis. Best Pract Res Clin Rheumatol 2003. 17:811-29.

30. Cutolo M. Anti-inflammatory mechanisms of methotrexate in rheumatoid arthritis. Ann Rheum Dis 2001;60:729-35.

31. Lee DM, Weinblatt ME. Rheumatoid arthritis. Lancet 2001;358:903-11.

32. Salama AH, Mahmoud AA, Kamel R. A novel method for preparing surface-modified fluocinolone acetonide loaded PLGA nanoparticles for ocular use: in vitro and in vivo evaluations. AAPS PharmSciTech 2016;17:1159-72.

33. Korsmeyer RW, Gurny R, Doelker E. Mechanisms of potassium chloride release from compressed, hydrophilic, polymeric matrices: effect of entrapped air. J Pharm Sci 1983;72:1189-91.

34. Sharma K, Hallan SS, Lal B. Development and characterization of floating spheroids of atorvastatin calcium loaded NLC for enhancement of oral bioavailability. Artif Cells Nanomed Biotechnol 2016;44:1448-56.

35. Neupane YR, Srivastava M, Ahmad N. Lipid based nanocarrier system for the potential oral delivery of decitabine: formulation design, characterization, ex vivo, and in vivo assessment. Int J Pharm 2014;477:601-12.

36. Soni K, Mujtaba A, Kohli K. Lipid drug conjugate nanoparticle as a potential nanocarrier for the oral delivery of pemetrexed diacid: formulation design, characterization, ex vivo, and in vivo assessment. Int J Biol Macromol 2017;103:139-51.

37. Peng X, Wen X, Pan X, Wang R, Chen B, Wu C. Design and in vitro evaluation of capsaicin transdermal controlled release cubic phase gels. AAPS PharmSciTech 2010;11:1405-10.

38. Tanaka $\mathrm{N}$, Imai $\mathrm{K}$, Okimoto $\mathrm{K}$. Development of novel sustainedrelease system, disintegration-controlled matrix tablet (DCMT) with solid dispersion granules of nilvadipine. J Controlled Release 2005;108:386-95.

39. Babu SAR, Karki SS. Anti inflammatory activity of various extracts of roots of calotropis procera against different inflammation models. Int J Pharm Pharm Sci 2011;3:191-4.

40. Rege A, Juvekar $\mathrm{P}$, Juvekar $\mathrm{A}$. In vitro antioxidant and antiarthritic activities of shilajit. Int J Pharm Pharm Sci 2012;4:650-3.

41. Irfan M, Verma S, Ram A. Preparation and characterization of ibuprofen loaded transferosome as a novel carrier for transdermal drug delivery system. Asian J Pharm Clin Res 2012;5:162-5.

42. Gayathri CR, Samuel V, Felix JW, Nirmala P. Comparative analysis of efficacy and safety of diacerein versus sadenosyl methionine in the management of osteoarthritis of knee joint. Int J Curr Pharm Res 2017;9:46-51.

43. Sanjaymitra PVSS, Ganesh GNK. Dissolution and solubility enhancement strategies: current and novel. J Crit Rev 2018;5:1-10.

44. https://www.ema.europa.eu/en/documents/scientificguideline/ich-q-1-r2-stability-testing-new-drug-substancesproducts-step-5_en.pdf [Last accessed on 10 Dec 2019]. 